\title{
Evaluation of Factors Affecting E-Bike Involved Crash and E-Bike License Plate Use in China Using a Bivariate Probit Model
}

\author{
Yanyong Guo, ${ }^{1,2}$ Jibiao Zhou, ${ }^{3,4}$ Yao $\mathrm{Wu}^{1}$ and Jingxu Chen ${ }^{1}$ \\ ${ }^{1}$ Jiangsu Key Laboratory of Urban ITS, Jiangsu Province Collaborative Innovation Center of Modern Urban Traffic Technologies, \\ Southeast University, Sipailou No. 2, Nanjing 210096, China \\ ${ }^{2}$ Department of Civil Engineering, University of British Columbia, 6250 Applied Science Lane, Vancouver, BC, Canada V6T $1 Z 4$ \\ ${ }^{3}$ School of Civil and Transportation Engineering, Ningbo University of Technology, Fenghua Rd. No. 201, Ningbo 315211, China \\ ${ }^{4}$ Key Laboratory for Traffic and Transportation Security of Jiangsu Province, Huaiyin Institute of Technology, Meicheng Rd. No. 1, \\ Huaiyin 223003, China
}

Correspondence should be addressed to Yanyong Guo; yanyong.guo@ubc.ca and Jibiao Zhou; zhoubiao666@126.com

Received 19 June 2017; Revised 21 October 2017; Accepted 24 October 2017; Published 21 November 2017

Academic Editor: Richard S. Tay

Copyright (C) 2017 Yanyong Guo et al. This is an open access article distributed under the Creative Commons Attribution License, which permits unrestricted use, distribution, and reproduction in any medium, provided the original work is properly cited.

\begin{abstract}
The primary objective of this study is to evaluate factors affecting e-bike involved crash and license plate use in China. E-bike crashes data were collected from police database and completed through a telephone interview. Noncrash samples were collected by a questionnaire survey. A bivariate probit (BP) model was developed to simultaneously examine the significant factors associated with e-bike involved crash and e-bike license plate and to account for the correlations between them. Marginal effects for contributory factors were calculated to quantify their impacts on the outcomes. The results show that several contributory factors, including gender, age, education level, driver license, car in household, experiences in using e-bike, law compliance, and aggressive driving behaviors, are found to have significant impacts on both e-bike involved crash and license plate use. Moreover, type of e-bike, frequency of using e-bike, impulse behavior, degree of riding experience, and risk perception scale are found to be associated with e-bike involved crash. It is also found that e-bike involved crash and e-bike license plate use are strongly correlated and are negative in direction. The result enhanced our comprehension of the factors related to e-bike involved crash and e-bike license plate use.
\end{abstract}

\section{Introduction}

In the last decades, there has been a rapid increase in the use of electric bicycles (e-bikes) in China. E-bikes provide users with convenient, flexible, and affordable mobility. They also have the advantages of low maintenance cost and easy parking [1-3]. Different from a regular bicycle, an e-bike has greater acceleration ability and operating speed. With the enhanced power assistance provided by lead acid batteries and motors, the e-bikes allow users to make longer distance trips. Despite their increased popularity and aforementioned merits, the injuries and deaths associated with e-bikes are experiencing a significant increase during the past ten years [4]. To reduce the number of e-bikes collisions, there is a need to understand the contributing factors underlying these events.
Research on e-bikes has focused on the growing use [5], the health and environmental effects $[6,7]$, and the aberrant riding behavior [8-11]. Safety research has focused on safety comparisons between e-bikes and regular bicycles [12-14], injury patterns among e-bike users ([15-17]; Feng et al., 2017), and modeling faults in e-bike fatal crashes [18]. The previous research showed that the crash likelihood of e-bikes was higher than that of regular bicycles. Furthermore, the e-bike crashes were found to be more severe than regular bicycle crashes. It was also found that most e-bikers who were involved in collisions were middle-aged and male. Although there are several systematic reviews on factors contributing to bicycle collisions [19-21], few research was focused on contributing factors to e-bikes collisions. The only study was conducted by $\mathrm{Hu}$ et al. [22] who found that age, road user 
category, traffic rule violations, crash mode, impact type, and vehicle type were related to the severity of e-bike injuries.

To improve e-bike safety on the road, traffic safety researches have recommended a license system to e-bikes [5, $8,11]$. The license plate can regulate e-bikes aberrant riding behavior such as red-light running and violating traffic laws. Although e-bikes are required to register and install a license plate by Vehicle Administration Bureau (VAB) in China, the outcome of e-bike plate use was unsatisfactory-majority of e-bikes were not registered in Chinese cities. In order to improve the low ratio of license plate use, evaluating and understanding the factors related to e-bike license plate use are required.

This paper sets out to examine three research questions. First, what are the risk factors associated with e-bike involved crash? Second, what are the contributing factors related to e-bike plate use? Third, what is the potential correlation between e-bike involved crash and e-bike license plate use due to the unobserved sharing factors that affect both ebike involved crash and license plate use? Three aspects of contributions are made in this research: (a) it is an innovative study to examine contributing factors affecting e-bike involved crash and e-bike license plate use at a disaggregated level; (b) there is limited research focusing on evaluating contributing factors related to e-bike involved crash and ebike license plate use; this study contributes to the literature by incorporating a comprehensive set of original covariates, including individual characteristics, household characteristics, travel information, riding behavior, and users' perception to examine the contributing factors; (c) this study employed a robust statistical technique. As such, the unobserved sharing factors that affect both e-bike involved crash and license plate use can be accounted for.

\section{Literature Review}

2.1. E-Bike Safety. In recent years, e-bike safety has been increasingly recognized by researchers due to its increasing usage and fatality rate. Previous studies showed that ebike involved crashes were more severe than bicycle related crashes [12, 22]. Weinert et al. [5] investigated safety perceptions of e-bike riders in Shijiazhuang, China. They found that females feel safer riding e-bikes to cross intersections than bicycles. Subsequently, Yao and Wu [9] conducted a self-reported questionnaire survey on e-bike riders in China. They established the relationships among safety attitude, risk perception, and aberrant riding behaviors of e-bike riders. The results showed that males were more likely to be involved in at-fault crashes than females, and e-bike riders with a driver's license were less likely to be involved in crashes. Wu et al. [8] and Guo et al. [11] have found that male e-bike riders were more likely to have risky behaviors than female riders. In addition, young and middle-aged e-bike riders were more prone to violating traffic rules.

Du et al. [15] examined e-bike riders' illegal behaviors in Suzhou. They reported that it was common for e-bike riders to violate traffic rules, which led to high crash risk. Risk factors related to e-bike involved crashes were investigated in the previous studies. Hu et al. [22] found that factors such as age, gender, and vehicle type were significantly associated with the e-bike/bicycle injuries. Using the police-recorded accidents data in Switzerland, Weber et al. [16] investigated the impacts of various factors such as type of accident, helmet usage, and injury severity on the e-bike accidents. Papoutsi et al. [17] conducted an analysis of e-bike accidents by focusing on the age, gender, time period, and cause of the accident using the crash data from a hospital in Switzerland. They found that most of the patients were male and the main causes of injury were self-accident. However, these studies have examined ebike involved crashes at an aggregate level.

2.2. E-Bike License Plate Use. With the aim to enhance the enforcement of e-bikes on road, e-bike license system was supported by several studies $[8,11,16]$. They also indicated that e-bike license can help promote e-bike riders' responsibility for road safety. Although the use of e-bikes has been recently increasing around the world, a review of the literatures regarding the e-bike license plate use found few studies. A recent study by Wu et al. [23] investigated the factors related to the registration of e-bike license in China. It was found that several factors such as gender, age group, education level, and automobile license had significant impacts on ebike registration. The study also reported four reasons for no registration of e-bike license. Since previous studies are limited in their capacity to explore factors associated with ebike license plate use, it is important to conduct a research on this topic to give an in-depth understanding of more factors related to e-bike license plate use.

\section{Data and Methods}

3.1. Data Collection. Data were collected in Ningbo, which is one of the biggest cities located on the east coast of China with a population of 7.8 million and an area of 9,817 square kilometers as of 2015. The city is also one of the richest cities in China. In 2015, the gross domestic product (GDP) reached 854.2 billion RMB ( $\$ 126.6$ billion). The e-bike ownership in Ningbo urban area reached 26.5 thousand in 2015. E-bike involved crashes reported by the traffic police are 1,541 , in which the fatalities account for $4.5 \%$. The e-bike crashes are more than bicycle crashes (854) but slightly less than motorcycle crashes (1676). However, the fatalities proportion of e-bike crashes is much higher than those of motorcycle and bicycle crashes $2.3 \%$ for bicycle crashes and $3.8 \%$ for motorcycle crashes).

In Ningbo, e-bikes are required to hang a license plate according to the local traffic laws. However, some e-bike riders do not respect the rule. In early 2015, the Ningbo Police Department (NBPD) launched the project IMPROVEMENT PROGRAMS OF NINGBO ELECTRIC BICYCLES in cooperation with Ningbo University of Technology (NBUT) with the aim to encourage e-bike license plate use and reduce e-bike involved crashes. The data collection was conducted along with the project. Data collection process in this study is divided into two parts: questionnaire survey to collect the noncrash e-bike riders' information and telephone interviews to collect the crash-involved e-bike riders' information. 
3.1.1. Survey of Noncrash E-Bikes. Questionnaire survey approach was used to collect information about noncrash ebike riders in Ningbo [24]. The questionnaire was designed primarily based on an extensive review of the literature and the results of preconducted focus group discussions. The questionnaire included five parts: (a) individual characteristics including gender, age, education level, occupation, and driver license (5 items); (b) household characteristics including number of e-bikes in household, car in household, and type of e-bike (3 items); (c) travel information including trip distance, trip purpose at weekdays and weekends, and frequency and experience in using e-bikes (5 items); (d) driving behaviors including law compliance, aggressive driving behaviors, impulse behavior, degree of riding experience, and surrounding traffic conditions (5 items); and (e) e-bike users' perception for e-bikes registration and crash risk (3 items) (see Appendix for details). Before the formal survey was launched, a pretest of 30 people was administered to identify potential problems with the questionnaire and to prevent biases. According to the feedback, the initial questionnaire was revised to make the questions clearer. Crosscheck questions were also set in the questionnaire in order to filter the self-report bias.

Students from NBUT were hired to conduct the faceto-face survey for two months (July and August) in 2015. Questionnaire investigators were placed at metro stations, shopping centers, and busy street corners. The random sampling technique was used in selecting the e-bike riders. The investigators were instructed to randomly select every fifth e-bike rider who passed through their sampling domain. Subsequently, the investigators explained to e-bike riders the purpose of the survey and then invited them to participate in the survey. After the e-bike riders accepted the invitation, the investigators explained in detail the meaning of relevant terminologies in the questionnaire, such as the aggressive driving behaviors, impulse behavior, and risk perception scale. After completing the questionnaire, respondents were offered a small gift as a token of appreciation. In order to eliminate the respondents' fear of information leakage, the survey was anonymous. After removing the sample of selfreport crash-involved e-bike users, 588 questionnaires with complete information were obtained.

3.1.2. Survey of Crash Related E-Bikes. E-bike crash data were provided by NBPD. Three criteria were used for extracting the e-bike crash data from the NBPD electric crash database: (a) at least one of the collision objects is e-bike; (b) the crash data period was consistent with the questionnaire survey period in order to match the survey time; (c) the collision records should contain the full information of date, time, location, collision types, crash severity, and a range of other items such as e-bike rider's gender, license plates number, identification number, and telephone number. In total, 276 injury crashes, 27 property damage only (PDO) crashes, and 7 fatal crashes were included in the crash database. A telephone interview was used to collect the crash-involved e-bike riders' information. The same questions in the questionnaire were used to get the users' demographic information, travel information, driving behaviors, and perception for e-bikes
TABLE 1: Cross-tabulation by e-bike involved crash and e-bike license plate use.

\begin{tabular}{lccc}
\hline \multirow{2}{*}{ E-bike license plate use } & \multicolumn{2}{c}{ E-bike involved crash } & Total \\
& Yes & No & \\
\hline Yes & 82 & 363 & 445 \\
No & 213 & 204 & 417 \\
Total & 295 & 567 & 862 \\
\hline
\end{tabular}

registration and crash risk. The fatal crash cases were removed from the database duo to the small sample size and no respondents. Only the PDO and injure crashes were selected in the telephone interview survey. In total, 303 samples with complete information were collected.

3.1.3. Questionnaire Reliability and Validity. The reliability of the questionnaire was measured using Cronbach $\alpha$ [25]. The result showed that $\alpha=0.623$ for the overall questionnaire, indicating that the questionnaire could be a sufficiently reliable tool for this study.

The validity of the questionnaire was measured with face validity and content validity. Specifically, face validity and content validity were measured using the expert assessment method. Two experts with rich experience in designing traffic questionnaire were invited to evaluate the readability, feasibility, clarity of wording, layout, and style of the questionnaire. A five-point Likert scale was used to measure each item from 1 (bad) to 5 (excellent). The average score was 4.3 , suggesting a high face validity of the questionnaire. Average congruency percentage (ACP) was used to measure the context validity of the questionnaire [26]. Experts suggest whether each question on a scale is relevant to the construct, computing the percentage of questions deemed to be relevant for each expert and then taking an average of the percentages across experts. The average ACP value was $91.7 \%$, indicating a high level of the context validity of the questionnaire.

3.1.4. Survey Results. The survey results were carefully examined in the laboratory for data selection. Cases with incomplete information, such as trip distance and trip purpose, were excluded. Furthermore, crosscheck questions played an important role in this process. Cases with logic problems, such as respondent who is young but retired, were excluded. In total, 862 samples, including 567 cases from the questionnaire survey and 295 cases from the telephone interview survey, were obtained after the data reduction. Among the 295 crash-involved cases, 271 samples are injury crashes and 24 samples are PDO. The male users are 183, accounting for $62 \%$ of the total users; and the females occupy $38 \%$. Most of the users are young e-bikers, accounting for $61 \%$, while the remaining $39 \%$ are middle-aged and old users.

Table 1 shows the cross-tabulation of the e-bike involved crash and e-bike license plate use. The e-bike involved crash and e-bike license plate use were defined as a binary indicator taking the value of either 1 (yes) or 0 (no). Overall, it was found that the e-bike involved crash rate was $34.2 \%$ and the e-bike license plate use rate was $51.6 \%$. The summary 
TABLE 2: Descriptive statistics for demographic information.

\begin{tabular}{|c|c|c|c|}
\hline Variable & Descriptive & Frequency & Percentage (\%) \\
\hline \multicolumn{4}{|l|}{ Individual characteristics } \\
\hline \multirow{2}{*}{ Gender } & Male & 438 & 50.8 \\
\hline & Female & 424 & 49.2 \\
\hline \multirow{3}{*}{ Age group } & Young $(<30)$ & 463 & 53.7 \\
\hline & Middle-aged (30-60) & 286 & 33.2 \\
\hline & Older $(>60)$ & 113 & 13.1 \\
\hline \multirow{4}{*}{ Education level } & High (postgraduate and higher) & 141 & 16.4 \\
\hline & Middle (junior college or undergraduate) & 343 & 39.8 \\
\hline & Middle-low (high school and junior middle school) & 294 & 34.1 \\
\hline & Low (junior middle school and lower) & 84 & 9.7 \\
\hline \multirow{7}{*}{ Occupation } & Student & 105 & 12.2 \\
\hline & Employee in enterprise/company & 244 & 28.3 \\
\hline & Officer & 119 & 13.8 \\
\hline & Self-employed & 143 & 16.6 \\
\hline & Freelance & 128 & 14.8 \\
\hline & Retired & 76 & 8.8 \\
\hline & Others & 47 & 5.5 \\
\hline \multirow{2}{*}{ Holding automobile driver license } & Yes & 552 & 64.0 \\
\hline & No & 310 & 36.0 \\
\hline \multicolumn{4}{|l|}{ Household characteristics } \\
\hline \multirow{2}{*}{ Number of e-bikes in household } & 1 & 506 & 58.7 \\
\hline & $>1$ & 356 & 41.3 \\
\hline \multirow{2}{*}{ Car in household } & Yes & 256 & 29.7 \\
\hline & No & 606 & 70.3 \\
\hline \multirow{2}{*}{ Type of e-bike } & Scooter style & 401 & 46.5 \\
\hline & Bicycle style & 461 & 53.5 \\
\hline
\end{tabular}

statistics of the valid samples are shown in Tables 2, 3, and 4. Among the valid samples, males account for $50.8 \%$ and females account for $49.2 \%$. The average age is 38.5 , with young, middle-aged, and older individuals accounting for $53.7 \%, 33.2 \%$, and $13.1 \%$, respectively. The characteristics of the valid samples are similar to those of the previous survey $[27,28]$, indicating that the participants are representative of the populations of e-bike riders.

3.2. Statistical Methods. The aim of this study is to simultaneously examine factors that affect both e-bike involved crash and e-bike license plate use. Discrete outcome modeling techniques were utilized as the dependent variables consist of binary indicator variables (i.e., e-bike involved crash/noncrash and e-bike license plate use/nonuse). In particular, a bivariate probit (BP) model was utilized in order to control the common unobserved factors that affect both the e-bike involved crash and license plate use. The BP model is an extension of the univariate binary probit and is designed to model binary dependent variables that may be simultaneously determined [22, 29-31]. If two separate univariate probit models were developed for each dependent variable, the correlation between the disturbances would be ignored, leading to inefficiency in model estimation [31]. The dependent variables for the BP model in this study are e-bike involved crash and e-bike license plate use, each coded as a binary indicator taking the value of either 1 or 0 . The BP model is given as

$$
\begin{aligned}
& Y_{1 i}^{*}=\boldsymbol{\beta}_{1} \mathbf{X}_{1 i}+\varepsilon_{1 i}, \\
& Y_{2 i}^{*}=\boldsymbol{\beta}_{2} \mathbf{X}_{2 i}+\varepsilon_{2 i},
\end{aligned}
$$

where $Y_{1 i}^{*}$ and $Y_{2 i}^{*}$ represent latent dependent variables; $\mathbf{X}_{1 i}$ and $\mathbf{X}_{2 i}$ are vectors of explanatory variables in the two models; $\boldsymbol{\beta}_{1}$ and $\boldsymbol{\beta}_{2}$ are vectors of coefficients associated with explanatory variables in the two models; $\varepsilon_{1 i}$ and $\varepsilon_{2 i}$ represent random error terms for both models, which follow the normal distribution with mean of 0 , variance of 1 , and correlation of $\rho$.

The cross-equation correlated error terms are

$$
\left[\begin{array}{l}
\varepsilon_{1 i} \\
\varepsilon_{2 i}
\end{array}\right] \sim N\left(\left[\begin{array}{l}
0 \\
0
\end{array}\right],\left[\begin{array}{ll}
1 & \rho \\
\rho & 1
\end{array}\right]\right) .
$$

The dependent variables $Y_{1 i}$ and $Y_{2 i}$ are observed if the latent variables $Y_{1 i}^{*}$ and $Y_{2 i}^{*}$ are greater than zero:

$$
Y_{1 i}= \begin{cases}1 & \text { if } Y_{1 i}^{*}>0 \\ 0 & \text { otherwise }\end{cases}
$$


TABLE 3: Descriptive statistics for travel information.

\begin{tabular}{|c|c|c|c|}
\hline Variable & Descriptive & Frequency & Percentage (\%) \\
\hline \multicolumn{4}{|l|}{ Travel information } \\
\hline \multirow{4}{*}{ Trip distance per day } & $<5 \mathrm{~km}$ & 353 & 41.0 \\
\hline & $5-10 \mathrm{~km}$ & 321 & 37.2 \\
\hline & $10-20 \mathrm{~km}$ & 134 & 15.5 \\
\hline & $>20 \mathrm{~km}$ & 54 & 6.3 \\
\hline \multirow{7}{*}{ Trip purpose at weekdays } & Go to work & 636 & 73.8 \\
\hline & Go to school & 120 & 13.9 \\
\hline & Official business & 15 & 1.7 \\
\hline & See a doctor & 3 & 0.4 \\
\hline & Go shopping & 45 & 5.2 \\
\hline & Go for entertainment & 19 & 2.2 \\
\hline & Others & 24 & 2.8 \\
\hline \multirow{7}{*}{ Trip purpose at weekends } & Visiting friends & 299 & 34.6 \\
\hline & Go for entertainment & 269 & 31.2 \\
\hline & Go shopping & 185 & 21.5 \\
\hline & See a doctor & 4 & 0.5 \\
\hline & Travelling & 75 & 8.7 \\
\hline & Taking exercise & 13 & 1.5 \\
\hline & Others & 17 & 2.0 \\
\hline \multirow{3}{*}{ Frequency of using e-bike (in one week) } & Frequently (more than 5 days) & 292 & 33.9 \\
\hline & Generally (3-4 days) & 159 & 18.4 \\
\hline & Occasionally (1-2 days) & 411 & 47.7 \\
\hline \multirow{4}{*}{ Experiences in using e-bike } & $>5$ years & 212 & 24.6 \\
\hline & $3-5$ years & 170 & 19.7 \\
\hline & $1-3$ years & 295 & 34.2 \\
\hline & $<1$ year & 185 & 21.5 \\
\hline
\end{tabular}

$$
Y_{2 i}= \begin{cases}1 & \text { if } Y_{2 i}^{*}>0 \\ 0 & \text { otherwise. }\end{cases}
$$

The parameters $\left(\boldsymbol{\beta}_{1}, \boldsymbol{\beta}_{2}\right.$, and $\left.\rho\right)$ in the bivariate BP model can be estimated by maximizing the log-likelihood function as follows:

$$
\ln L=\sum \ln \Phi_{2}\left[q_{1 i} \beta_{1} X_{1 i}, q_{2 i} \beta_{2} X_{2 i}, q_{1 i} q_{2 i} \rho\right],
$$

where $\left[q_{1 i} \beta_{1} X_{1 i}, q_{2 i} \beta_{2} X_{2 i}, q_{1 i} q_{2 i} \rho\right]$ represents the cumulative density function for the bivariate standard normal distribution with correlation $\rho ; q_{1 i}=2 Y_{1 i}-1$ and $q_{2 i}=2 Y_{2 i}-1$. Therefore, $q_{j i}=1$ if $y_{j i}=1$ and $q_{j i}=0$ if $y_{j i}=0$, for $j=1,2$.

The correlation parameter $\rho$ measures the correlation between e-bike involved crash and license plate use after the effects of the explanatory variables included in the model have been accounted for. When explaining the model results, the sign of the estimated $\beta$ for each independent variable controls the effect that variable has on e-bike involved crash and license plate use. A positive $\beta$ indicates that the variable would tend to increase the probability of e-bike involved crash and license plate use and a negative $\beta$ indicates that the variable would tend to decrease the probability of e-bike involved crash and license plate use.
In order to quantitatively get the impact of the explanatory variables on the outcomes, marginal effects are calculated for variables of interest in the BP model. Since all explanatory variables in this study are binary indicators or can be converted into binary indicators, the marginal effects are interpreted as the change in the expected value of a dependent variable caused by changing an explanatory variable from zero to one while keeping other variables at their mean value $[22,30]$. Marginal effects can be calculated by

$$
\begin{aligned}
& E\left[Y_{1} \mid Y_{2}=1, X=1\right]-E\left[Y_{1} \mid Y_{2}=1, X=0\right], \\
& E\left[Y_{1} \mid Y_{2}=0, X=1\right]-E\left[Y_{1} \mid Y_{2}=0, X=0\right] .
\end{aligned}
$$

\section{Model Estimation and Discussion of Results}

To assess the factors associated with e-bike involved crash and e-bike license plate use, a BP model was estimated. The explanatory variables and descriptive statistics were shown in Tables 2, 3, and 4. SAS 9.2 software was utilized to estimate the model. Table 5 shows the estimate results of the BP model. Only variables that were significant at a $95 \%$ confidence level were included in the estimated model. 
TABLE 4: Descriptive statistics for riding behavior and perception.

\begin{tabular}{|c|c|c|c|}
\hline Variable & Descriptive & Frequency & Percentage (\%) \\
\hline \multicolumn{4}{|l|}{ Riding behavior } \\
\hline \multirow{3}{*}{ Law compliance } & Strong & 576 & 66.8 \\
\hline & Fair & 201 & 23.3 \\
\hline & Weak & 85 & 9.9 \\
\hline \multirow{3}{*}{ Aggressive driving behaviors* } & Frequently & 71 & 8.2 \\
\hline & Generally & 171 & 19.9 \\
\hline & No & 620 & 71.9 \\
\hline \multirow{3}{*}{ Impulse behavior ${ }^{* *}$} & Frequently & 41 & 4.8 \\
\hline & Generally & 96 & 11.1 \\
\hline & No & 725 & 84.1 \\
\hline \multirow{3}{*}{ Degree of riding experience } & Skilled & 527 & 61.2 \\
\hline & General & 301 & 34.9 \\
\hline & New driver & 34 & 3.9 \\
\hline \multirow{2}{*}{ Surrounding traffic conditions } & Heavy traffic & 478 & 55.5 \\
\hline & Light traffic & 384 & 44.5 \\
\hline \multicolumn{4}{|l|}{ Perception } \\
\hline \multirow{2}{*}{ Risk perception scale ${ }^{* * *}$} & High & 387 & 44.9 \\
\hline & Low & 475 & 55.1 \\
\hline \multirow{2}{*}{ Registration fee } & High & 314 & 36.4 \\
\hline & Low & 548 & 63.6 \\
\hline \multirow{2}{*}{ Time for license registration } & $\leq 30 \mathrm{~min}$ & 577 & 66.9 \\
\hline & $>30 \mathrm{~min}$ & 285 & 33.1 \\
\hline
\end{tabular}

${ }^{*}$ E-bike drivers deliberately behave in such a manner that increases the risk of conflicts. ${ }^{* *}$ Ability of self-control and level of tolerance for other people's fault. ${ }^{* * * *}$ Perceived likelihood of accident and danger.

The correlation parameter of the error terms of e-bike involved crash and license plate use was found to be significant $(\rho=-0.475 ; p<0.001)$. The result indicated that several commonly shared unobserved factors were captured by the error terms of the two latent dependent variables. Moreover, the correlation parameter was negative, indicating that an ebike license use can decrease the likelihood of e-bike involved crash. This finding provides enhanced evidence for e-bike safety improvements by using license plate in China. The ebike license plate was supported by several previous studies $[5,9,11]$.

As shown in Table 5, there are fifteen significant variables in the e-bike involved crash model and eleven significant variables in the e-bike license plate use model. The coefficients estimated in Table 5 provide a general sense of the direction of impacts of contributory factors on the outcomes. The positive coefficient indicates the increase of probability of the outcome with the increase of the corresponding variable and vice versa. Table 6 shows marginal effects for these variables to quantify their impacts.

4.1. Individual Characteristics. Regarding gender, males are found to be $17.7 \%$ points more likely to be involved in e-bike crash compared to females, which is consistent with previous researches [17, 18]. Wang et al. [18] pointed out that male riders are more likely to be at fault than female riders in e-bike related crashes. It was also found that males were $28.5 \%$ points less likely to use e-bike license plate than females. This finding is supported by other studies $[9,17,23]$. However, this result is in contrast to the motorcycle license plate use. As noted by de Rome et al. [32], the number of males who registered motorcycle license plate is 6.8 times that of females in NSW.

Young e-bike riders $(<30)$ are $12.4 \%$ points more likely to be involved in e-bike involved crash and $44.2 \%$ points less likely to use e-bike license plate compared to elder riders. This finding is consistent with previous studies [22, 33, 34]. Bernhoft and Carstensen [34] found that middle-aged and older e-bike riders were more cautious and experienced than younger riders who tend to take more risks, which leads to a higher crash possibility by youth. Moreover, young e-bike riders are afraid of being recorded for risky or illegal driving behavior by the police or camera after installing license plate, resulting in lower possibility of using e-bike license plate by them. Although the high likelihood of crash by young e-bike riders was found in this paper, some studies have found that the injury severity was greater in the older age group than in the younger group $[16,22]$.

E-bike riders with high education level (postgraduate and higher) have $47.9 \%$ points higher possibility of using ebike license plate than other education level groups. Simultaneously, they have $16.9 \%$ points lower possibility of being involved in e-bike crash. This is an interesting finding and is consistent with the finding of $\mathrm{Wu}$ et al. [23]. It pointed out that people with high education background, who usually receive more education about safety and order in traffic, cared more about e-bike safety [35]. As well, they are aware of 


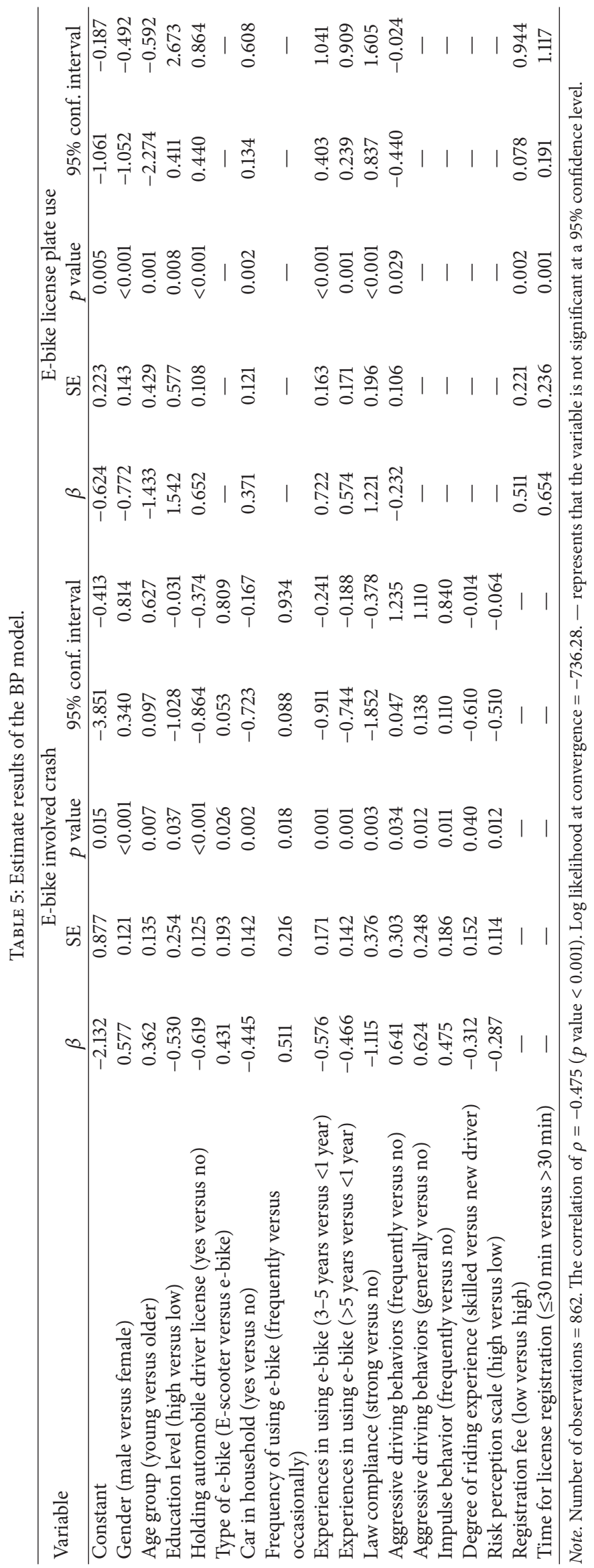


TABLE 6: Marginal effects for the BP model.

\begin{tabular}{lcc}
\hline Variable & E-bike involved crash & E-bike license plate use \\
\hline Gender (male versus female) & 0.177 & -0.285 \\
Age group (Young versus older) & 0.124 & -0.442 \\
Education level (high versus low) & -0.169 & 0.479 \\
Holding automobile driver license (yes versus no) & -0.225 & 0.243 \\
Type of e-bike (E-scooter versus e-bike) & 0.156 & - \\
Car in household (yes versus no) & -0.165 & 0.137 \\
Frequency of using e-bike (frequently versus occasionally) & 0.182 & - \\
Experiences in using e-bike (3-5 years versus <1 year) & -0.203 & 0.267 \\
Experiences in using e-bike (>5 years versus <1 year) & -0.164 & 0.221 \\
Law compliance (strong versus no) & -0.425 & 0.433 \\
Aggressive driving behaviors (frequently versus no) & 0.163 & -0.025 \\
Aggressive driving behaviors (generally versus no) & 0.152 & - \\
Impulse behavior (frequently versus no) & 0.144 & - \\
Degree of riding experience (skilled versus new driver) & -0.107 & - \\
Risk perception scale (high versus low) & -0.089 & - \\
Registration fee (low versus high) & - & - \\
Time for license registration ( $\leq 30$ min versus $>30$ min) & - & 0.146 \\
\hline
\end{tabular}

- represents that the variable is not significant.

the helpfulness of e-bike license plate use on road safety and traffic management. This finding is similar to previous study on motorcycles demonstrating that motorcycle safety training program could reduce motorcycle crashes and crash severity [36]. The result suggests that traffic safety education is an effective countermeasure to improve e-bike safety and to promote e-bike license plate use.

E-bike riders who hold an automobile driver license tend to be $22.5 \%$ points less likely to be involved in e-bike crash and $24.3 \%$ points more likely to use e-bike license plate compared to those without driver license. This result is confirmed by Yao and $\mathrm{Wu}$ [9] who showed that e-bike riders with a driver license were 1.51 times less likely to be involved in e-bike accidents than those without a driver license. The contribution of driving experience to the safety of two-wheelers was also found in other studies with motorcyclists [37]. Regarding the e-bike license plate use, drivers were more familiar with the regulatory processes of motorized transportation. Furthermore, there are small barriers to register e-bike license plate [38]. The results suggest the benefit of automobile driver license for reducing the likelihood of e-bike involved crash and increase the probability of e-bike license use.

4.2. Household Characteristics. Scooter style e-bikes are found to be $15.6 \%$ points more likely to be involved in e-bike crash than the bicycle style ones. This finding is consistent with the past studies $[9,11,39]$ which found that the e-scooters were more crash-prone due to their higher operating speeds.

E-bike riders with a car in household tend to be $13.7 \%$ points less likely to be involved in e-bike crash and $12.5 \%$ points more likely to use e-bike license plate than those who have no car. The reason would be that car drivers who are aware of the uncomfortable feeling caused by presence of e-bikes on automobile lanes would support e-bike license plate use to restrain e-bikers' unsafe behaviors [23].

4.3. Travel Information. E-bike riders with an experience of 3-5 years are $20.3 \%$ points less likely to be involved in ebike crash and $26.7 \%$ points more likely to use license plate. Simultaneously, E-bike riders with an experience of more than 5 years are $16.4 \%$ points less likely to be involved in ebike crash and $22.1 \%$ points more likely to use license plate. The findings indicate that experienced e-bike riders have lower possibility to be involved in e-bike crash; however, this trend decreases along with time. This can be explained as ebike riders are distracted due to familiarly with this tool when they use e-bikes for a long time. The results also demonstrate that experienced e-bike riders prefer to use e-bike license plate.

The frequency of travel by e-bike is significantly associated with e-bike crash likelihood. Riders who frequently travel by e-bike have $18.2 \%$ points higher possibility to be involved in e-bike crash. The result is comparable to bicycle crashes, which reported higher crash likelihood for frequent cyclists compared to those who cycle less than one day per week [12]. The finding is quite intuitive, since frequent use of e-bikes increases the exposure for e-bike involved crash.

It is also interesting to find that some notable variables (e.g., trip distance, trip purpose, and trip mode) were not found to significantly affect e-bike involved crash and e-bike license plate use.

4.4. E-Bike Riders' Behaviors. E-bike riders with a strong law compliance degree are found to be $42.5 \%$ points less likely to be involved in e-bike crash and $43.3 \%$ points more likely to use e-bike license plate. Several studies reported the 
contribution of law compliance to the safety of e-bikes [22, 39]. Yao and $\mathrm{Wu}$ [9] found that e-bike riders who have less positive attitudes to traffic regulation have higher possibility of crash. The result also supports the fact that improving ebike riders' traffic law compliance could promote the bike license plate use.

E-bike riders who frequently have aggressive driving behaviors and impulse behaviors tend to be $16.3 \%$ points and $14.4 \%$ points more likely to be involved in e-bike crash. As found in previous studies, the aberrant riding behaviors by ebikes increase the risk of conflicts, resulting in high likelihood of crash $[10,11]$. E-bike riders with frequent aggressive driving behaviors are found to be $2.5 \%$ points less likely to use e-bike license plate. As mentioned previously, e-bike riders do not want such risky behaviors to be recorded by the police after installing license plate.

Skilled e-bike riders are found to be $10.7 \%$ points less likely to be involved in e-bike crash than new drivers. The interpretation is that skilled e-bike riders have more experience in dealing with the crash risk compared to new drivers. The finding is consistent with previous study on motorcycle which found that new motorcycle drivers were more likely to be involved in fatal crashes [40].

4.5. E-Bike Riders' Perception. E-bikers with high risk perception scale are $8.9 \%$ points less likely to be involved in e-bike crash and $10 \%$ points more likely to use e-bike license plate. Previous study by Yao and $\mathrm{Wu}$ [9] has confirmed this result by stating that e-bike riders who have high risk perception were less likely to engage in e-bike crash.

Regarding the registration fee, e-bike riders who are satisfied with it tend to be $14.6 \%$ points more likely to use an e-bike license plate compared to those who are not satisfied with the fee. As for the registration time, e-bike riders who think it takes a short time to register a license plate have $17.9 \%$ points higher possibility to use a license plate compared to those who think the registration takes much time. The results suggest that a high-quality registration service, such as a short registration time and less fee, is a useful countermeasure to improve license plate use.

4.6. Implications. Currently, although the e-bike has mobility, economic, and environmental advantages, it always suffers from the safety issues. This research contributes to the growing literature on e-bike safety and fills in the gap in extant literature that seldom examines the contributing factors to e-bike crash and license plate use. Findings of the study can offer valuable insights into the underlying relations between risk factors and e-bike crashes, as well as the contributing factors related to e-bike plate use. They can also help implement more effective countermeasures to mitigate the e-bike crashes and improve the e-bike plate use. Furthermore, the models calibrated in this study can also be used to predict the likelihood of e-bike crash and license plate use.

Based on the findings in this study, countermeasures aimed at addressing e-bike safety and low ratio of e-bike license plate use are proposed: (a) safety campaigns could be launched to increase e-bike riders' awareness of law and their awareness of benefits from e-bike license plate use, especially for the young e-bike users who have high likelihood of being involved in crash; (b) it is recommended to enforce e-bike license plate to scooter style e-bikes considering the result that this type of e-bike is more likely to be involved in crash; and (c) a more effective registration system, as well as a highquality registration service, should be developed to make the e-bike license plate registration process easier and quicker.

\section{Conclusions}

In China, the growing popularity of e-bikes raises safety concerns. This present study applied a BP model to simultaneously examine factors affecting both e-bike involved crash and e-bike license plate use. The BP model allowed for consideration of correlation between e-bike involved crash and license plate use by capturing commonly shared unobserved characteristics between them. The correlation parameter was found to be statistically significant and negative in direction, indicating that e-bike license plate use can decrease the probability of e-bike involved crash. Furthermore, marginal effects for contributory variables were calculated to quantify their impacts on the outcomes.

The findings of this study provided insights into the factors associated with the e-bike involved crash and license plate use. The results of the BP model showed various contributory factors. In the e-bike involved crash model, fifteen variables including gender, age, education level, driver license, type of e-bike, car in household, frequency of using ebike, experiences in using e-bike, law compliance, aggressive driving behavior, impulse behavior, degree of riding experience, and risk perception scale were found to be statistically significant. In the e-bike license plate use model, eleven variables including gender, age, education level, driver license, car in household, experiences in using e-bike, law compliance, aggressive driving behavior, registration fee, and registration time were found to be statistically significant.

Some limitations should be addressed in future work. First, the survey was conducted in one Chinese city. Due to the different operation characteristics of e-bikes across cities, additional survey is needed in other cities to understand the heterogeneity of e-bike involved crash and e-bike license plate use among cities. Second, due to the time cost and financial and human consumption, the infrastructure characteristics were not collected in this study. As pointed out by a systematic review [20], the most important factor related to bicyclemotorized vehicle collisions was infrastructure characteristics. As e-bikes and bicycles share some similar features, these characteristics maybe also contribute to e-bike collisions. As such, the infrastructure characteristics, including interaction, roundabout, road section, urban or metropolitan roads or arterial roads, bicycle lanes/path, physical barrier, and structured medians, should be further examined. Third, the reasons for no use of e-bike license plate were neglected in this study. Future studies are needed to better understand why e-bike riders do not register license plates. Furthermore, the extension of this study would be to examine the unobserved heterogeneity across e-bike riders. Recent works provided the framework of a random parameter bivariate ordered probit model [41, 42]. Under this framework, parameters' effects on 
e-bike involved crash and license plate use across e-bike riders can be estimated.

\section{Appendix}

\section{Questions in the Questionnaire Survey and Telephone Interview}

Date: -

Time: -

Location: -

investigator: -

Individual Characteristics

(1) Gender:
(1) Male $\square$
(2) Female $\square$

(2) Age group:
(1) $<30 \square$
(2) $30-60 \square$
(3) $>60 \square$

(3) Education level:
(1) postgraduate and higher $\square$
(2) junior college or undergraduate $\square$
(3) high or junior middle school $\square$
(4) junior middle school lower $\square$

(4) Occupation:
(1) Student $\square$
(2) Employee in enterprise/company $\square$
(3) Officer $\square$
(4) Self-employed $\square$
(5) Freelance $\square$
(6) Retired $\square$
(7) Others $\square$

(5) Holding automobile driver license:
(1) Yes $\square$
(2) No $\square$

\section{Household Characteristics}

(1) Number of e-bikes in household:
(1) $1 \square$
(2) $>1 \square$

(2) Car in household:

(1) Yes $\square$
(2) No $\square$

(3) Type of e-bike:

(1) Scooter style $\square$

(2) Bicycle style $\square$

Travel Information

(1) Trip distance per day:
(1) $<5 \mathrm{~km} \square$
(2) $5-10 \mathrm{~km} \square$
(3) $10-20 \mathrm{~km} \square$
(4) $>20 \mathrm{~km} \square$

(2) Trip purpose at weekdays:
(1) Go to work $\square$
(2) Go to school $\square$
(3) Official business $\square$
(4) See a doctor $\square$
(5) Go shopping $\square$
(6) Go for entertainment $\square$
(7) Others $\square-$.

(3) Trip purpose at weekends:
(1) Visiting friends $\square$
(2) Go for entertainment $\square$
(3) Go shopping $\square$
(4) See a doctor $\square$
(5) Travelling $\square$
(6) Taking exercise $\square$
(7) Others $\square$

(4) Frequency of using e-bike (in one week):
(1) $>5$ day $\square$
(2) 3-4 days $\square$
(3) 1-2 days $\square$

(5) Experiences in using e-bike:
(1) $>5$ years $\square$
(2) 3-5 years $\square$
(3) 1-3 years $\square$
(4) $<1$ year $\square$

Riding Behavior

(1) Law compliance:
(1) Strong $\square$
(2) Fair $\square$
(3) Weak $\square$ 
(2) Aggressive driving behaviors:
(1) Frequently $\square$
(2) Generally $\square$
(3) No $\square$

(3) Impulse behavior:
(1) Frequently $\square$
(2) Generally $\square$
(3) No $\square$

(4) Degree of riding experience:
(1) Skilled $\square$
(2) General $\square$
(3) New driver $\square$

(5) Surrounding traffic conditions:
(1) Heavy traffic $\square$
(2) Light traffic $\square$

\section{Perception}

(1) Risk perception scale:
(1) High $\square$
(2) Low $\square$

(2) Registration fee:
(1) High $\square$
(2) Low $\square$

(3) Time for license registration:
(1) $\leq 30 \min \square$
(2) $>30 \min \square$

Other Information. -

\section{Conflicts of Interest}

The authors declare that there are no conflicts of interest regarding the publication of this paper.

\section{Acknowledgments}

This research was sponsored by the Public Technology Application Foundation of Zhejiang Province of China (no. 2016C33256), the Social Science Foundation of Zhejiang Province of China (no. 18NDJC107YB), the Key Laboratory for Traffic and Transportation Security of Jiangsu Province (nos. TTS2016-04 and TTS2017-07), the National Natural Science Foundation of China (no. 71701046), the China Postdoctoral Science Foundation funded project (2017M571644), the Fundamental Research Funds for the Central Universities (no. YBJJ1458), the Scientific Innovation Research of College Graduates in Jiangsu Province (no. KYLX_0173), and the Science and Technological Innovation Projects on College Students in Zhejiang Province (no. 2017R424023).

\section{References}

[1] A. A. Parker, "Electric power-assisted bicycles reduce oil dependence and enhance the mobility of the elderly," in Proceedings of the 29th Australasian Transport Research Forum (ATRF), Melbourne, Australia, September 2006.

[2] R. C. Cherry and M. He, "Alternative methods of measuring operating speed of electric and traditional bikes in Chinaimplications for travel demand models," Journal of the Eastern Asia Society for Transportation Studies, vol. 8, pp. 1424-1436, 2010.

[3] M. H. Zaki, T. Sayed, and X. Wang, "Computer vision approach for the classification of bike type (motorized versus nonmotorized) during busy traffic in the city of Shanghai," Journal of Advanced Transportation, vol. 50, no. 3, pp. 348-362, 2016.

[4] Z. Feng, R. P. Raghuwanshi, Z. Xu, D. Huang, C. Zhang, and T. Jin, "Electric-bicycle-related injury: a rising traffic injury burden in China," Injury Prevention, vol. 16, no. 6, pp. 417-419, 2010.

[5] J. X. Weinert, M. Chaktan, X. Yang, and C. R. Cherry, "Electric two-wheelers in China: effect on travel behavior, mode shift, and user safety perceptions in a medium-sized city," Transportation Research Record, vol. 2038, pp. 62-68, 2007.

[6] S. Ji, C. R. Cherry, M. J. Bechle, Y. Wu, and J. D. Marshall, "Electric vehicles in China: emissions and health impacts," Environmental Science \& Technology, vol. 46, no. 4, pp. 20182024, 2012.

[7] C. R. Cherry, J. X. Weinert, and Y. Xinmiao, "Comparative environmental impacts of electric bikes in China," Transportation Research Part D: Transport and Environment, vol. 14, no. 5, pp. 281-290, 2009.

[8] C. Wu, L. Yao, and K. Zhang, “The red-light running behavior of electric bike riders and cyclists at urban intersections in China: an observational study," Accident Analysis \& Prevention, vol. 49, no. 1, pp. 186-192, 2012.

[9] L. Yao and C. Wu, "Traffic safety for electric bike riders in China: attitudes, risk perception, and aberrant riding behaviors," Transportation Research Record, vol. 2314, pp. 49-56, 2012.

[10] L. Bai, P. Liu, Y. Chen, X. Zhang, and W. Wang, "Comparative analysis of the safety effects of electric bikes at signalized intersections," Transportation Research Part D: Transport and Environment, vol. 20, no. 2, pp. 48-54, 2013.

[11] Y. Guo, P. Liu, L. Bai, C. Xu, and J. Chen, "Red light running behavior of electric bicycles at signalized intersections in China," Transportation Research Record, vol. 2468, pp. 28-37, 2014.

[12] J. P. Schepers, E. Fishman, P. den Hertog, K. Klein Wolt, and A. L. Schwab, "The safety of electrically assisted bicycles compared to classic bicycles," Accident Analysis \& Prevention, vol. 73, no. 1, pp. 174-180, 2014.

[13] C. B. Langford, J. Chen, and C. Cherry, "Comparing safetyrelated riding behaviors on bicycles and electric bicycles," in Transportation Research Board 94th Annual Meeting, Transportation Research Board, Washington DC, USA, 2015.

[14] J. Van Oijen, R. Lankhuijzen, and O. Van Boggelen, Facts about Electrically Assisted Bicycles, Dutch Bicycle Council, Utrecht, Netherlands, 2013.

[15] W. Du, J. Yang, B. Powis et al., "Understanding on-road practices of electric bike riders: an observational study in a developed city of China," Accident Analysis \& Prevention, vol. 59, no. 1, pp. 319326, 2013. 
[16] T. Weber, G. Scaramuzza, and K.-U. Schmitt, "Evaluation of ebike accidents in Switzerland," Accident Analysis \& Prevention, vol. 73, no. 1, pp. 47-52, 2014.

[17] S. Papoutsi, L. Martinolli, C. T. Braun, and A. K. Exadaktylos, "E-bike injuries: experience from an urban emergency department-a retrospective study from Switzerland," Emergency Medicine International, vol. 2014, Article ID 850236, 5 pages, 2014.

[18] C. Wang, C. Xu, J. Xia, and Z. Qian, "Modeling faults among e-bike-related fatal crashes in China," Traffic Injury Prevention, vol. 18, no. 2, pp. 175-181, 2017.

[19] S. Handy, B. van Wee, and M. Kroesen, "Promoting Cycling for transport: research needs and challenges," Transport Reviews, vol. 34, no. 1, pp. 4-24, 2014.

[20] G. Prati, V. Marín Puchades, M. De Angelis, F. Fraboni, and L. Pietrantoni, "Factors contributing to bicycle-motorised vehicle collisions: a systematic literature review," Transport Reviews, vol. 1, pp. 1-25, 2017.

[21] C. C. O. Reynolds, M. A. Harris, K. Teschke, P. A. Cripton, and M. Winters, "The impact of transportation infrastructure on bicycling injuries and crashes: A review of the literature," Environmental Health: A Global Access Science Source, vol. 8, no. 1, article no. 47, pp. 1-19, 2009.

[22] F. Hu, D. Lv, J. Zhu, and J. Fang, "Related risk factors for injury severity of e-bike and bicycle crashes in Hefei," Traffic Injury Prevention, vol. 15, no. 3, pp. 319-323, 2014.

[23] Y. Wu, Y. Guo, Z. Li, and K. Chen, "nvestigating the factors related to the registration of electric bicycle licenses in China," in Transportation Research Board 94th Annual Meeting, Transportation Research Board, Washington DC, USA, 2015.

[24] S. Haustein and M. Møller, "E-bike safety: individual-level factors and incident characteristics," Journal of Transport \& Health, vol. 3, no. 3, pp. 386-394, 2016.

[25] E. G. Carmines and R. A. Zeller, Reliability and Validity Assessment, vol. 17, SAGE Publications, Thousand Oaks, Calif, USA, 1979.

[26] W. J. Popham, Criterion-Referenced Measurement, Prentice Hall, Englewood Cliffs, NJ, USA, 1978.

[27] S. Zhang, L. Guo, and C. Lu, Monthly Transportation Report of Ningbo City, Urban Administration, Bureau of Passenger Transport of Ningbo City, Ningbo, China, 2014.

[28] Y. Guo, J. Zhou, Y. Wu, Z. Li, and J. Liu, "Identifying the factors affecting bike-sharing usage and degree of satisfaction in Ningbo, China," PLoS ONE, vol. 12, no. 9, pp. 1-19, 2017.

[29] K. Gkritza, "Modeling motorcycle helmet use in Iowa: evidence from six roadside observational surveys," Accident Analysis \& Prevention, vol. 41, no. 3, pp. 479-484, 2009.

[30] B. J. Russo, J. J. Kay, P. T. Savolainen, and T. J. Gates, “Assessing characteristics related to the use of seatbelts and cell phones by drivers: application of a bivariate probit model," Journal of Safety Research, vol. 49, no. 1, pp. 137-142, 2014.

[31] H. Greene W, Econometric Analysis, Pearson Education India, New York, NY, USA, 8th Edition edition, 2017.

[32] L. de Rome, M. Fitzharris, M. Baldock, R. Fernandes, A. Ma, and J. Brown, "Characteristics of motorcycle riders in NSW," in Proceeding of the 2013 Australasian Road Safety Research, Policing \& Education Conference, NSW Centre for Road Safety, Brisbane, Queensland, Australia, 2013.

[33] D. Yagil, "Gender and age-related differences in attitudes toward traffic laws and traffic violations," Transportation Research Part F: Traffic Psychology and Behaviour, vol. 1, no. 2, pp. 123-135, 1998.
[34] I. M. Bernhoft and G. Carstensen, "Preferences and behaviour of pedestrians and cyclists by age and gender," Transportation Research Part F: Traffic Psychology and Behaviour, vol. 11, no. 2, pp. 83-95, 2008.

[35] N. Dragutinovic and D. Twisk, "The effectiveness of road safety education: a literature review," in SWOV Institute for Road Safety Research, pp. 1-85, Amsterdam, The Netherlands, 2006.

[36] J. C. McDavid, B. A. Lohrmann, and G. Lohrmann, "Does motorcycle training reduce accidents? evidence from a longitudinal quasi-experimental study," Journal of Safety Research, vol. 20, no. 2, pp. 61-72, 1989.

[37] P. Lardelli-Claret, J. J. Jiménez-Moleón, J. De Dios Lunadel-Castillo, M. García-Martín, A. Bueno-Cavanillas, and R. Gálvez-Vargas, "Driver dependent factors and the risk of causing a collision for two wheeled motor vehicles," Injury Prevention, vol. 11, no. 4, pp. 225-231, 2005.

[38] X. Chen and J. Zhao, "Bidding to drive: Car license auction policy in Shanghai and its public acceptance," Transport Policy, vol. 27, no. 27, pp. 39-52, 2013.

[39] O. Wu and Q. Liu, "Electric bicycle related injury and risk factors in Hangzhou," Journal of Environmental \& Occupational Medicine, vol. 9, no. 1, pp. 1-17, 2012.

[40] L. J. Paulozzi, "The role of sales of new motorcycles in a recent increase in motorcycle mortality rates," Journal of Safety Research, vol. 36, no. 4, pp. 361-364, 2005.

[41] P. Anastasopoulos, M. Karlaftis, J. Haddock, and F. Mannering, "Household automobile and motorcycle ownership analyzed with random parameters bivariate ordered probit model," Transportation Research Record, no. 2279, pp. 12-20, 2012.

[42] B. J. Russo, P. T. Savolainen, W. H. Schneider, and P. C. Anastasopoulos, "Comparison of factors affecting injury severity in angle collisions by fault status using a random parameters bivariate ordered probit model," Analytic Methods in Accident Research, vol. 2, no. 1, pp. 21-29, 2014. 


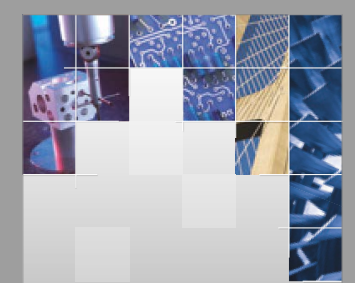

\section{Enfincering}
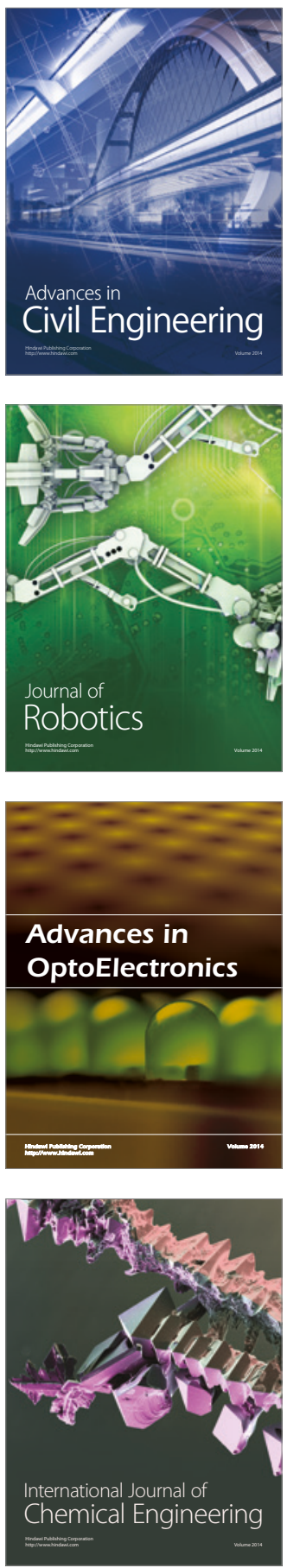

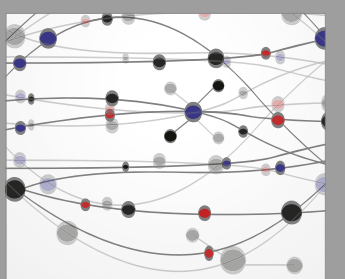

The Scientific World Journal

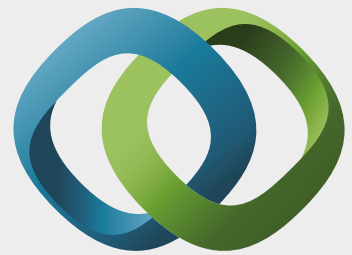

\section{Hindawi}

Submit your manuscripts at

https://www.hindawi.com
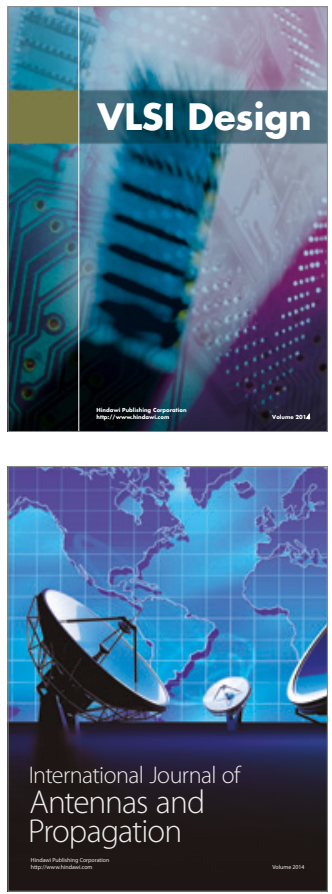

\section{Rotating}

Machinery
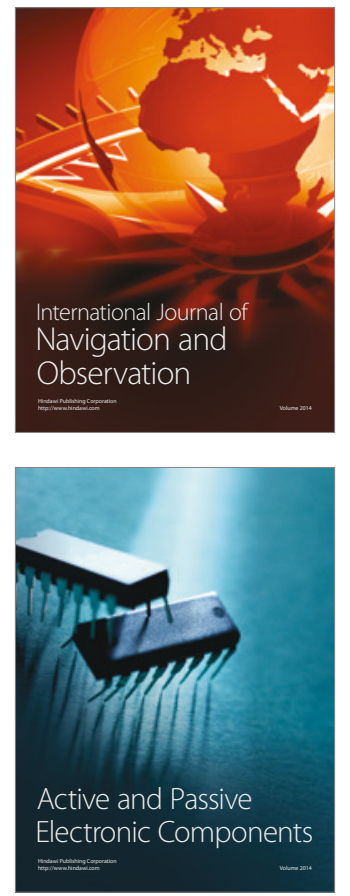
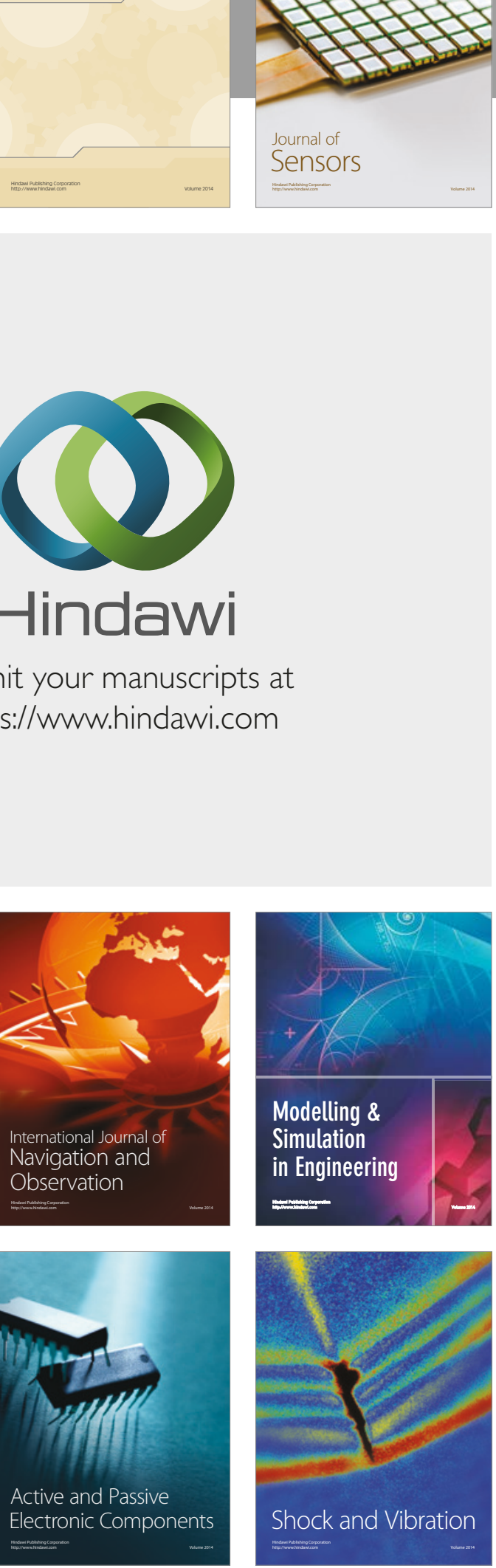
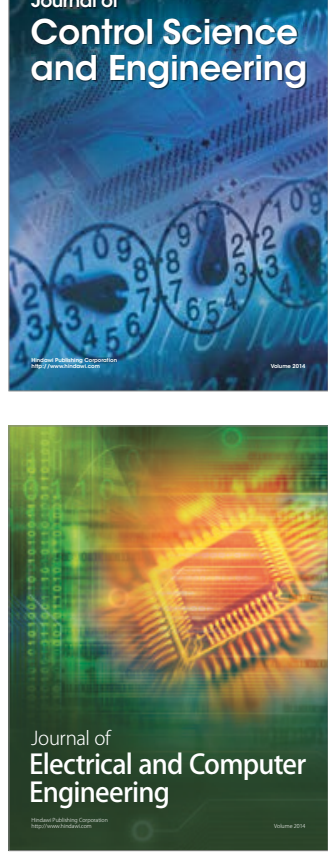

Distributed

Journal of

Control Science

and Engineering
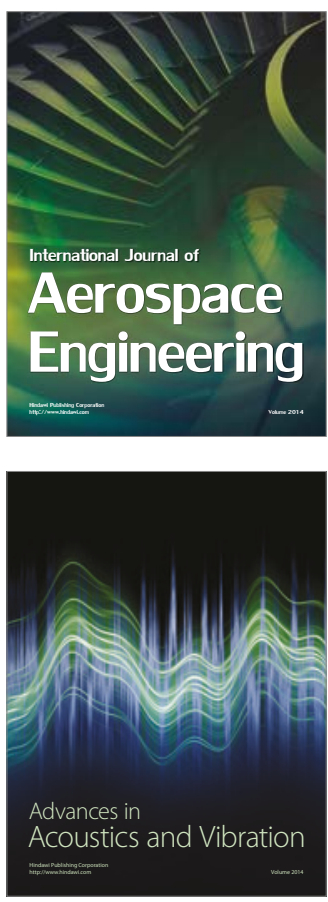

Sensor Networks 